\title{
Prevalence of Depression, Anxiety and Stress among School Going Adolescents and their Relationship to Socioeconomic Status
}

\author{
Saroj Swapnil Salelkar', Sagar Atmaram Borker ${ }^{2}$ \\ ${ }^{1}$ Insurance Medical Officer, ESIC Scheme, Goa, India. \\ ${ }^{2}$ Associate Professor in PSM, ABVIMS and Dr. RML hospital, Delhi, India. \\ DOI: https://doi.org/10.24321/2349.2880.202017
}

\section{I $\quad \mathbf{N} \quad \mathbf{F} \quad \mathbf{O}$}

\section{Corresponding Author:}

Saroj Swapnil Salelkar, ESIC Scheme, Goa, India.

E-mail Id:

saroj18183@gmail.com

Orcid Id:

https://orcid.org/0000-0002-0842-8891

How to cite this article:

Salelkar SS, Borker Prevalence of Depression, Anxiety and Stress among School Going Adolescents and their Relationship to Socioeconomic Status. Ind J Youth Adol Health 2020; 7(4): 8-14.

Date of Submission: 2021-02-07

Date of Acceptance: 2021-03-02

\section{$\begin{array}{llllllll}\mathbf{A} & \mathbf{B} & \mathbf{S} & \mathbf{T} & \mathbf{R} & \mathbf{A} & \mathbf{C} & \mathbf{T}\end{array}$}

Introduction: Adolescence is a phase involving risk taking, autonomy, adventure and efforts to fit into adulthood. Physical and emotional changes, peers, social media, education, family expectations etc. make individuals vulnerable.

Aims: To study the prevalence of depression, anxiety and stress in school going adolescents from 9th -12th standard from Bagdogra, to examine the association with family factors and Socio Economic Status and to identify the co-morbidities between Depression, Anxiety and Stress.

Methods: A cross sectional study was carried out using DASS-21 scale on a total of 231 students. In addition, a self-structured questionnaire on family structure and socio economic status was administered and SPSS software was used for analysis.

Result: Overall, $76.2 \%$ had at least one of the mental morbidities under study. Depression was significantly more common in class $12^{\text {th }},(28.4 \%)$, $9^{\text {th }}(28.4 \%) \& 10^{\text {th }}(27.6 \%)$ and stress was significantly common in $12^{\text {th }}$ $(55.4 \%) \& 10^{\text {th }}(55.2 \%)$. There was no significant difference in relation to age, sex, family structure and socioeconomic status. All mental morbidities more frequently occurred in combination with each other, rather than exclusively. Depression most frequently occurred with stress (8 times) followed by anxiety (4 times), whereas anxiety was 6 times more likely to occur with stress.

Conclusions: Almost 3 out of 4 children had symptoms related to at least one of the mental morbidities discussed. Depression and stress was significantly more prevalent in students answering board exams (class $10^{\text {th }}$ and $12^{\text {th }}$ ) than those not answering board exams. Depression, Anxiety and Stress were highly correlated with each other.

Keywords: Depression, Anxiety, Stress, Adolescents, DASS 21, Mental Health 


\section{Introduction}

The second decade of life is an exploratory and highly challenging phase marked by rebellion, aggression, conflict and stress. Mental health conditions account for $16 \%$ of the global burden of disease among adolescents, half of which start by 14 years but remain undetected. ${ }^{1}$ In India, psychiatric disorders among adolescents is around $7.3 \%{ }^{2}$ Hormonal and emotional changes, social conditions, peers, career goals etc., make an adolescent vulnerable. The boom of social media and the ongoing pandemic of COVID-19 has added to the woes. Adolescents comprise about $20 \%$ of a country's population. ${ }^{3}$ Mental health disorders can persist into adulthood and affect day-to-day and social functioning of an individual ${ }^{4}$ and is a risk factor for suicidal tendencies.

\section{Aim of the study}

- To study the prevalence of depression, anxiety and stress in school going adolescents from $9^{\text {th }}-12^{\text {th }}$ standard.

- To examine the association of depression, anxiety and stress with family factors and Socio Economic Status and

- To identify the co-morbidities between depression, anxiety and stress among adolescents.

\section{Materials and Methods}

A cross sectional study was conducted in schools from January to February, 2020. All students (aged 13-17 years) of grades $9^{\text {th }}, 10^{\text {th }}, 11^{\text {th }}$ and $12^{\text {th }}$ were included whereas participants undergoing treatment for mental illness were excluded from the study.

Sample size was calculated based on the WHO report on Mental Health Status of Adolescents in South-East Asia, wherein the varied prevalence of psychiatric morbidity was approximately $8 \%$ to $25 \% .{ }^{1}$ The mean prevalence with relative error of $5 \%$ was calculated to estimate the sample size. Although 211 was the minimum sample size estimated, 240 participants consented to participate.

Fourteen Schools from the area providing education from $9^{\text {th }}$ to $12^{\text {th }}$ standard with boys as well as girl students were eligible for the study, of which four were selected using lottery method. Fifteen students per class were selected from each school via Systematic Random Sampling. Altogether, 60 students were selected from each school from all classes. The same process was repeated in all four schools until a total sample size of 240 students was obtained. Of these, nine participants were excluded from the study due to the history of medications for mental illness (2), age 18 years and above (3) incomplete data (4). Final sample size obtained was 231 .

A self-structured questionnaire on approximate monthly income, family structure including occupation and education of parents, number of siblings and socio-economic status was prepared based on Modified Kuppuswamy Scale 2019. ${ }^{5}$
DASS-21 questionnaire ${ }^{6}$ was used to obtain prevalence of depression, anxiety and stress.

Ethical Clearance for the study was obtained from Institutional Ethics Review Committee of North Bengal Medical College. Permission from school principals and management, Written Informed Consent from parents and Written Informed Assent from the participants was taken prior to the study. Confidentiality and anonymity of the candidate was maintained throughout data collection, data entry and analysis.

Data entry was done in Microsoft Excel 2016 spreadsheet and was crosschecked for errors, double entry, missed entry and wrong entry. Data was analyzed using the SPSS software in the form of frequency tables, charts and crosstabs. For statistical significance proportion, chi square tests, correlation and odds ratios were computed.

\section{Result}

Table 1, shows the socio demographic profile of this sample. Of the total participants $33.3 \%$, students were 17 years of age and females comprised $50.2 \%$ of the participants.

Table I.Demographic Profile and Family Structure of the Participants

\begin{tabular}{|c|c|c|c|}
\hline $\begin{array}{l}\text { Charact- } \\
\text { eristic }\end{array}$ & Parameter & No. & Percentage \\
\hline \multirow{2}{*}{ Age } & $\begin{array}{l}\text { Early Adolescence } \\
(13-14)\end{array}$ & 35 & 15.2 \\
\hline & $\begin{array}{c}\text { Middle Adolescence } \\
(15-17)\end{array}$ & 196 & 84.8 \\
\hline \multirow{2}{*}{ Sex } & Male & 115 & 49.8 \\
\hline & Female & 116 & 50.2 \\
\hline \multirow{4}{*}{$\begin{array}{c}\text { Class } \\
\text { Studying } \\
\text { in }\end{array}$} & $9^{\text {th }}$ & 57 & 24.7 \\
\hline & $10^{\text {th }}$ & 58 & 25.1 \\
\hline & $11^{\text {th }}$ & 60 & 26 \\
\hline & $12^{\text {th }}$ & 56 & 24.2 \\
\hline \multirow{6}{*}{$\begin{array}{l}\text { Education } \\
\text { of } \\
\text { Head of } \\
\text { Family }\end{array}$} & Illiterate & 3 & 1.3 \\
\hline & Middle School Level & 13 & 5.6 \\
\hline & High School Level & 66 & 28.6 \\
\hline & $\begin{array}{l}\text { Intermediate/ Post } \\
\text { High School Diploma }\end{array}$ & 70 & 30.3 \\
\hline & $\begin{array}{c}\text { Graduate/ Post } \\
\text { Graduate }\end{array}$ & 77 & 33.3 \\
\hline & Professional Degree & 2 & 0.9 \\
\hline \multirow{4}{*}{$\begin{array}{c}\text { Occupation } \\
\text { of Head } \\
\text { of Family }\end{array}$} & Unemployed & 2 & 0.9 \\
\hline & Unskilled Worker & 3 & 1.3 \\
\hline & Semi-Skilled Worker & 7 & 3 \\
\hline & Skilled Worker & 14 & 6.1 \\
\hline
\end{tabular}




\begin{tabular}{|c|c|c|c|}
\hline & Clerk/ Shop/ Farm & 155 & 67.1 \\
\hline & Semi Professional & 48 & 20.8 \\
\hline & Professional & 2 & 0.9 \\
\hline \multirow{2}{*}{$\begin{array}{l}\text { Family Size } \\
\text { (No of } \\
\text { Members) }\end{array}$} & Up to 4 & 137 & 59.3 \\
\hline & More than 4 & 94 & 40.7 \\
\hline \multirow{2}{*}{$\begin{array}{l}\text { Parental } \\
\text { Status }\end{array}$} & Single Parents & 8 & 3.5 \\
\hline & Both Parents & 223 & 96.5 \\
\hline \multirow{2}{*}{$\begin{array}{l}\text { Sibling } \\
\text { Status }\end{array}$} & Single Child & 24 & 10.4 \\
\hline & Non Single Child & 207 & 89.6 \\
\hline \multirow{6}{*}{$\begin{array}{c}\text { Socio } \\
\text { Economic } \\
\text { Status }\end{array}$} & I (Upper Class) & 3 & 1.3 \\
\hline & $\begin{array}{c}\text { II (Upper Middle } \\
\text { Class) }\end{array}$ & 131 & 56.7 \\
\hline & $\begin{array}{c}\text { III (Lower Middle } \\
\text { Class) }\end{array}$ & 86 & 37.2 \\
\hline & $\begin{array}{l}\text { IV (Upper Lower } \\
\text { Class) }\end{array}$ & 11 & 4.8 \\
\hline & V (Lower Class) & 0 & 0 \\
\hline & Total & 231 & 100 \\
\hline
\end{tabular}

Symptoms of depression, anxiety and stress were not significantly related to age (depression $\chi 2=3.5889$ $p=0.166215$; anxiety $\chi 2=5.088 p=0.078552$; stress $\chi 2=4.5525$ $\mathrm{p}=0.102668$ ) or sex (depression $\chi 2=2.406 \mathrm{p}=0.662$; anxiety $\chi 2=3.670 p=0.453$; stress $\chi 2=1.4459 p=0.694$ ) of the participant. This could be due to similar response, susceptibility and coping mechanisms to acute and chronic stress in adolescents of 13-17 years and both sexes.
Table 2, shows prevalence of depression, anxiety and stress according to class of study. This result was significant for depression and stress $(\chi 2=17.821 p=0.000)(\chi 2=13.168$ $p=0.004$ ) respectively; thus, a significant difference exists between occurrence of symptoms of depression, stress and class of study. Regarding anxiety, most (27.1\%) students with anxiety were from class 10 . However, these findings were not statistically significant $(\chi 2=3.970 p=0.265)$.

On comparison between board classes (class $10^{\text {th }}$ and $12^{\text {th }}$ ) and non-board classes ( $9^{\text {th }}$ and $11^{\text {th }}$ ) it was observed that depression and stress in board classes was higher (65.8\% \& 55.3\% respectively) in comparison to non-board classes (50.4\% \& $37.6 \%$ respectively), with mild, moderate and severe forms more common. These findings were statistically significant. (depression $\chi 2=10.7672, p=0.0293$, stress $\chi 2=8.304 p=0.0401)$. Hence, a significant difference exists between occurrence of symptoms of depression, stress and class of participant.

Anxiety in board classes was higher, (53.8\% i.e. 63/117 and $61.4 \%$ i.e. $70 / 114$ respectively), with mild and moderate forms more common. However, these findings were not statistically significant $(\chi 2=3.1574 p=0.53183)$.

The reasons for these findings could be due to increased tension of approaching board exams of class 10th and 12th, with fear of failure or poor performance in the examinations which are believed to be a major milestone for future study and career opportunities. Presence of symptoms in class 9th may be due to upcoming final examinations, anticipation of promotion to the next class and the built up of pressure regarding the academic goals and examination stress which

Table 2.Prevalence of Depression, Anxiety and Stress according to Class of Study

\begin{tabular}{|c|c|c|c|c|c|}
\hline \multirow{3}{*}{ Morbidity } & \multicolumn{4}{|c|}{ Class } & \multirow[b]{2}{*}{ Total } \\
\hline & $9^{\text {th }}$ & $10^{\text {th }}$ & $11^{\text {th }}$ & $12^{\text {th }}$ & \\
\hline & N (\%) & N (\%) & N (\%) & N (\%) & N (\%) \\
\hline \multicolumn{6}{|l|}{ Depression } \\
\hline Present & $38(28.4)$ & $37(27.6)$ & $21(15.7)$ & $38(28.4)$ & 134 (100) \\
\hline Absent & $19(19.6)$ & $21(21.6)$ & $39(40.2)$ & $18(18.6)$ & 97 (100) \\
\hline
\end{tabular}

Chi Square $=17.821, \mathrm{df}=3, \mathrm{p}$-value $\mathbf{0} \mathbf{0 . 0 0 0}$ result is highly significant

\begin{tabular}{|c|c|c|c|c|c|}
\hline Anxiety & & & & & \\
\hline Present & $35(26.3)$ & $36(27.1)$ & $28(21.1)$ & $34(25.6)$ & $133(100)$ \\
\hline Absent & $22(22.4)$ & $22(22.4)$ & $32(32.7)$ & $22(22.4)$ & $98(100)$ \\
\hline
\end{tabular}

Chi Square $=3.970, \mathrm{df}=3, \mathrm{p}$ value $=0.265$ result is not significant

\begin{tabular}{|c|c|c|c|c|c|}
\hline Stress & & & & & \\
\hline Present & $28(26.2)$ & $32(29.9)$ & $16(15)$ & $31(29)$ & $107(100)$ \\
\hline Absent & $29(23.4)$ & $26(21)$ & $44(35.5)$ & $25(20.2)$ & $124(100)$ \\
\hline Total & $57(24.7)$ & $58(25.1)$ & $60(26)$ & $56(24.2)$ & $231(100)$ \\
\hline
\end{tabular}

Chi Square $=13.168, \mathrm{df}=3, \mathrm{p}$ value $=0.004$ result is significant 
will ensue. However, these aspects need further investigation and are beyond the scope of this study.

Regarding prevalence of mental morbidity according to socio economic status depression, anxiety and stress was higher in the students of upper and upper middle class i.e. $54.5 \%$, $54.9 \%$ and $58.9 \%$ respectively. However, these findings were not statistically significant (depression $\chi 2=1.63343 p=0.2012$; anxiety $\chi 2=1.2539 p=0.2628$; stress $\chi 2=0.0619 p=0.8035$ ).

Prevalence of depression, anxiety and stress was not related to family size $(\chi 2=1.89779 p=0.1683)$, number of siblings $(\chi 2=0.4237 p=0.51509)$, parental status (i.e. either single parent or both parents) $(\chi 2=0.5842 \mathrm{p}=0.4446)$ and family income $(\chi 2=8.4119 \mathrm{p}=0.2094)$.

However, 24 children were a single child of which, $62.5 \%$ (15/24) were males. All belonged to SES II and III. Of these, $66.66 \%$ ( 16 out of 24 ) had depression of which around $54 \%$ (13 out of 24) had moderate to extremely severe forms. Anxiety and stress symptoms were present in 50\% (12). Hence, it may be possible that being a single child makes a person more prone to mental health problems especially depression. This could be due to a lack of companionship and confidante, leading to less of discussion and sharing of emotional issues. However, an in-depth study with adequate sample size is needed to explore these findings.

Prevalence of mental morbidities with reference to family factors like education ( $\chi 2=1.39197 p=0.4986)$ \& occupation of father $(\chi 2=0.4835 p=0.7852)$ and mother education $(\chi 2=0.1681 p=0.9826)$ and occupation $(\chi 2=0.2482 p=0.6183)$ were also not found to have any statistical significance. However, 8 (3.5\%) participants had single parents, of these, six $(75 \%)$ were single mothers. it was observed that both students with single father and $83 \%$ (i.e. 5/ 6) students with single mother had symptoms of depression, anxiety and stress, of which most were moderate -severe- extremely severe in nature. Most of the participants (7 out of 8) belonged to the socio economic class II and III. Hence, students with single parents $(87.5 \%$ i.e. $7 / 8)$ could be more prone to mental health problems due to lack of a role model, lack of care and attention, lack of sharing of emotional issues etc. However, these findings too need a detailed study with appropriate sample size.

Hence, symptoms of depression, anxiety and stress could occur due to reasons unrelated to education, occupation and socio economic status like genetic susceptibility, academic stress, peer pressure, parental pressure etc. which need to be further explored.

Figure 1, shows prevalence of depression, anxiety and stress in the study participants. It is observed that $76.2 \%$ participants had symptoms of at least one mental morbidity under study. Hence, more frequently, most of the individuals will usually have a combination of two or more mental morbidities, rather than exclusive presence of any one.

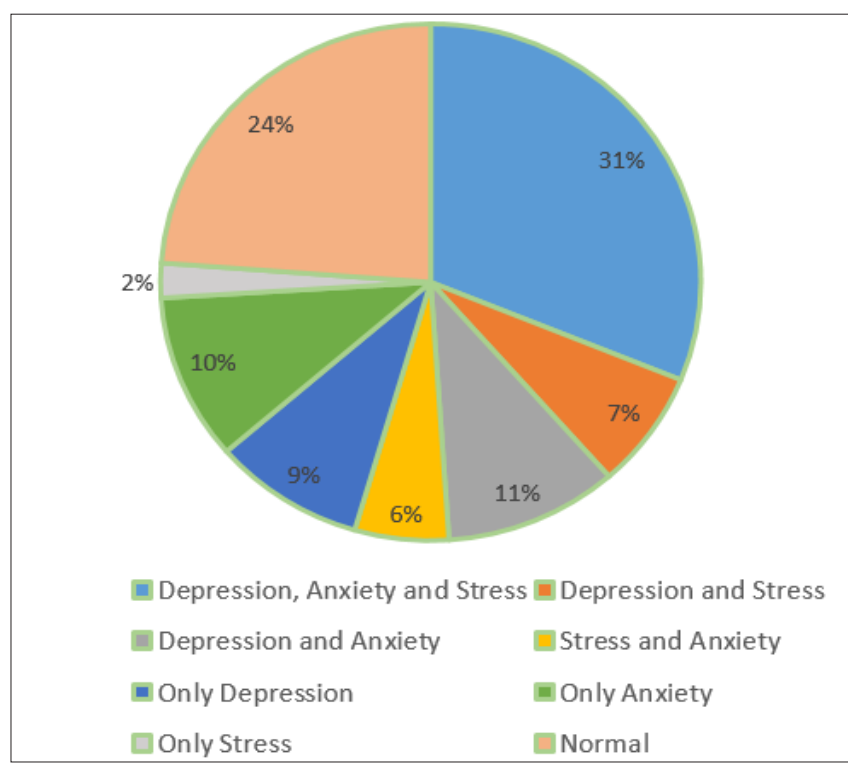

Figure I.Prevalence of Depression, Anxiety and Stress

Table 3, shows comorbidity between occurrence of depression in relation to anxiety and stress Individuals with anxiety were 4 times $(O R=4)$ more likely to suffer from depression and individuals with stress were 8 times $(O R=8)$ more likely to have depression symptoms. These finding were highly significant $(p=0.000)$, hence suggesting that there is significant association between occurrences of depression and anxiety or stress symptoms.

On similar comparison between anxiety and stress, it was seen that $79.4 \%(85)$ of the individuals have anxiety along with stress. Anxiety only was present in $38.7 \%$ (48) of the individuals whereas stress alone was present in $20.6 \%$ (22) of the individuals. Individuals with anxiety were 6 times more likely to have stress. This finding was highly significant ( $\chi 2=39.001 \mathrm{p}=0.000)$.

Pearson's correlation coefficient showed a significant linear relationship between Depression, Anxiety and Stress (at 0.01 level). Overall, there was moderately positive correlation between depression- anxiety $(r=0.598, p=0.000, n=231)$, depression- stress $(r=0.654, p=0.000, n=231)$ and anxietystress. $(r=0.649, p=0.000, n=231)$. The strength of the association was moderately strong $(.5<|r|<0.9)$. Hence, increase in either one of the variables correlated with increase of other variables. These findings were highly significant.

Occurrence of depression and anxiety is usually a response to chronic stress and individual vulnerability and coping mechanisms. Stressors in this study could be exam tension, worry about exam performance, expectations from parents, competitiveness associated with exam results etc. Genetic factors and other social conditions like parenting, abuse, peer relationships, relationships with teachers etc. can predispose an individual to occurrence, of depression, anxiety and stress symptoms. 
Table 3.Presence of Depression in Relation to Anxiety and Stress

\begin{tabular}{|c|c|c|c|}
\hline \multirow{2}{*}{ Morbidity } & \multicolumn{2}{|c|}{ Depression } & \multirow{2}{*}{$\begin{array}{c}\text { Total } \\
\mathbf{N}(\%)\end{array}$} \\
\hline & Present N (\%) & Absent N (\%) & \\
\hline \multicolumn{4}{|l|}{ Anxiety } \\
\hline Present & $96(71.6)$ & $37(38.1)$ & $133(57.6)$ \\
\hline Absent & $38(28.4)$ & $60(61.8)$ & $98(42.4)$ \\
\hline \multicolumn{4}{|c|}{ Chi square statistic $=25.848, \mathrm{df}=1, \mathrm{p}$ value $=0.000$ result highly significant Odds Ratio $=4.0967, \mathrm{Cl} ; 2.350-7.1428$} \\
\hline \multicolumn{4}{|l|}{ Stress } \\
\hline Present & $89(66.4)$ & $18(18.6)$ & $107(46.3)$ \\
\hline Absent & $45(33.6)$ & $79(81.4)$ & $124(53.7)$ \\
\hline Total & $134(100)$ & $97(100)$ & $231(100)$ \\
\hline
\end{tabular}

\section{Discussion}

In this study, about $31 \%$ had all the mental morbidities under study, $23.8 \%$ individuals did not have symptoms of any of the morbidities while, $76.2 \%$ of the individuals had at least one of the mental health morbidities. These findings were almost similar to observations made by a study amongst rural adolescents in Maharashtra (depression $53.9 \%$, anxiety $59.7 \%$, stress $43.8 \%$ and normal $27.3 \%$. Single condition $18.4 \%, 23.9 \%$ two conditions \& $30.4 \%$ all three conditions). ${ }^{7}$

However, the findings of this study are higher as compared to figures obtained from National Mental Health Survey of India, ${ }^{2}$ wherein prevalence of psychiatric disorders was $7.3 \%$. In addition, a study among higher secondary school students in Manipur observed Depression, Anxiety and Stress prevalence to be $19.5 \%, 24.4 \%$, and $21.1 \%$ respectively. ${ }^{8}$ However, some studies found $50 \%$ of the participants to have psychological problems. ${ }^{9,10}$

A study conducted in school going adolescents in Chandigarh, found prevalence of depression, anxiety and stress as $65.53 \%, 80.85 \%$ and $47.02 \%$, respectively, with overall comorbidity between depression and anxiety $57.65 \%,{ }^{11}$ which was higher in comparison to the findings of this study.

Regarding gender, there was no statistically significant difference in Depression, Anxiety and Stress in both sexes. These findings were consistent with findings of other studies. ${ }^{2,7,12,13}$ However, these findings were contradictory to studies showing higher prevalence of depression, anxiety and or stress in females ${ }^{8,11,14,15}$ or males. ${ }^{16,17}$

In this study, there was no statistically significant difference in occurrence of Depression, Anxiety and Stress concerning age. These findings were contradictory to findings in school going adolescents of Chandigarh where overall trend showed that stress increased with age. ${ }^{11}$
According to class of study, it was found that depression was more prevalent in classes $9^{\text {th }}(66.7 \%) 12^{\text {th }}(67.9 \%)$ and stress was more prevalent in class $12^{\text {th }}$ and 10 th $(55.4$ \& $55.2 \%$ respectively). Students of class $11^{\text {th }}$ had comparatively lower prevalence of depression, anxiety and stress (35\% i.e. $21 / 60,46.7 \%$ i.e. $28 / 60$ and $26.7 \%$ i.e. $16 / 60$ respectively).

These findings are consistent with some studies wherein students of $10^{\text {th }}$ and $12^{\text {th }}$ were found to have more prevalence of depression, anxiety and stress. ${ }^{8}$ Further, study amongst Chandigarh school adolescents concluded that depression and stress were higher in board classes than non-board classes with depression higher in class 12, anxiety higher in class 10 and stress higher in $9^{\text {th }}$ class, ${ }_{11}^{11}$ which were almost similar to the findings of this study. Study among school children in Tiruchirappalli, India observed that half of the respondents of class $12^{\text {th }}$ had moderate level of stress. ${ }^{15}$

In this study, no significant difference was observed between presence of symptoms of Depression, Anxiety and Stress with family size, maternal education and employment, paternal education and occupation, family income and socio economic class. These findings are similar to findings obtained by couple of other studies as well. ${ }^{12,15}$

Depression, Anxiety and Stress were significantly correlated with each other. This is in line with findings obtained in other studies. ${ }^{12,14}$

School based mental health interventions and internetbased prevention and treatment programs are effective for symptoms of anxiety and depression. ${ }^{18}$ Screening programs, helplines, school education and life skill programs can be instrumental in bringing about diagnosis of mental illness and suicide prevention. Early identification and treatment of individuals with suicidal tendencies is crucial. Programs like Stop a Suicide Today, National Suicide Prevention Lifeline etc. need to be established and adequately programmed to reach the target individuals. ${ }^{19}$ 


\section{Conclusion}

Thus, almost 3 out of 4 children from $9^{\text {th }}$ to $12^{\text {th }}$ class had symptoms related to at least one of the mental morbidities discussed i.e. either depression, anxiety and or stress. Depression and stress was found to be significantly more prevalent in students answering board exams than those not answering board exams. Students of class $11^{\text {th }}$ had comparatively lower prevalence of Depression, Anxiety and Stress. In addition, more than one morbidity was more commonly observed rather than only one of the mental morbidities. Depression, Anxiety and Stress were highly correlated with each other.

As this study data was collected during Jan-Feb which is the period just 1-2 months before the scheduled annual/ board exams it is possible that this study has been able to capture the most stressful phase during the participant's academic session, hence reflecting a higher prevalence of mental morbidities.

\section{Limitation}

As the study population was limited to school going students of standard $9^{\text {th }}-12^{\text {th }}$ (13-17 years) from Bagdogra, the findings cannot be extrapolated to non-school going adolescents, students from other classes, different ages, other areas and populations and rural regions. As this is a cross sectional study, causal effect cannot be interpreted.

DASS-21 scale was used for data collection and the findings cannot be used for allocation of participants to diagnostic categories according to classification systems like International Classification of Diseases (ICD) or Diagnostic and Statistical manual of Mental Disorders (DSM). Only mental morbidities of Depression, Anxiety and Stress were observed and other mental health issues were not discussed. The reasons for occurrence of Depression, Anxiety and Stress were not explored in this study.

\section{Recommendation}

Based on these conclusions, further studies that could address reasons of Depression, Anxiety and Stress including effects of single parenting and single child status are recommended. In addition, strategies to decrease stress factors for students should be planned. The recent proposal of the New Education Policy by the government of India could be a step in this direction towards improving mental health of adolescents, and comparative results of the same in the future would indicate the benefits that the Policy may achieve.

\section{Acknowledgement}

I would like to express my sincere gratitude to all the people who were involved in supporting me during the course and the process of this study. The management, principals, teachers and other staff of the schools for their cooperation, participants and their parents for taking time to participate in the study. I also wish to thank the Medical Officers attached to the institutions for taking a special interest and time to support and provide insights to the students on mental illnesses and ways to handle them.

\section{Conflict of Interest: None}

\section{References}

1. World Health Organization: Mental health status of adolescents in South-East Asia: Evidence for action. New Delhi: World Health Organization, Regional Office for South-East Asia; 2017.84p. Licence: CC BY-NC-SA 3.0 IGO. Retrieved from https://apps.who.int/iris/ handle/10665/254982

2. Gururaj G, Varghese $M$, Benegal $V$ et al. NMHS collaborators group. National Mental Health Survey of India, 2015-16: Prevalence, patterns and outcomes. Bengaluru, National Institute of Mental Health and Neuro Sciences, NIMHANS Publication No. 129, 2016. Retrieved from: https://www.researchgate.net/ publication/325128785_National_Mental_Health_ Survey_of_India_2015-16_Prevalence_Pattern_and_ Outcomes

3. World Health Organization (WHO) Health for the World's Adolescents, 2014(cited 2020 Jul 07) Retrieved from: https://apps.who.int/adolescent/second-decade

4. Krapić N, Hudek-Knežević J, Kardum I. Stress in Adolescence: Effects on Development. In: James D. Wright (editor-in-chief). International Encyclopedia of the Social \& Behavioral Sciences 2015: $2^{\text {nd }}$ edition, Vol 23. Oxford: Elsevier. 562-569. Retrieved from https:// www.researchgate.net/publication/304190804_Stress_ in_Adolescence_Effects_on_Development.

5. Wani RT. Socioeconomic status scales-modified Kuppuswamy and Udai Pareekh's scale updated for 2019. J Family Med Prim Care 2019; 8: 1846-1849. DOI: 10.4103/jfmpc.jfmpc_288_19. Retrieved from https://www.jfmpc.com/article.asp?issn=2249-4863;ye $\operatorname{ar}=2019$; volume $=8$;issue $=6$; page $=1846$; epage $=1849$ ;aulast=Wani

6. Lovibond SH, Lovibond PF. Manual for the Depression Anxiety \& Stress Scales. (2 ${ }^{\text {nd }}$ Ed.) Sydney: Psychology Foundation (1995). Retrieved from: https://journals. plos.org/plosone/article/file?type=supplementary \&id=info:doi/10.1371/journal.pone.0219193.s004

7. Shaikh BM, Doke PP, Gothankar JS. Depression, anxiety, stress, and stressors among rural adolescents studying in Pune and a rural block of Nanded district of Maharashtra, India. Indian J Public Health 2018; 62: 311-314. DOI: 10.4103/ijph.IJPH_174_17. Retrieved from https://www.ijph.in/article.asp?issn=0019-557X; year $=2018$; olume $=62$;issue $=4$; spage $=311$; epage $=314$ ;aulast=Shaikh 
8. Kumar KS, Akoijam BS. Depression, Anxiety and Stress Among Higher Secondary School Students of Imphal, Manipur. Indian Journal of Community Medicine 2017: 42(2): 94-96. Retrieved from https://pubmed.ncbi.nlm. nih.gov/28553025/

9. Arun P, Garg R, Chavan BS. Stress and suicidal ideation among adolescents having academic difficulty. Ind Psychiatry Journal 2017: 26(1): 64-70. Retrieved from: https://www.ncbi.nlm.nih.gov/pmc/articles/ PMC5810170/

10. Zare VR, Ramesh B, Kokiwar P. Assessment of "depression, anxiety and stress" among students of schools at RHTC area catered by private medical college in South India. International Journal of Community Medicine and Public Health 2018: 5(7): 1-3. DOI: http:// dx.doi.org/10.18203/2394-6040.ijcmph20182658

11. Sandal RK, Goel NK, Sharma MJ et al. Prevalence of Depression, Anxiety and Stress among school going Adolescent in Chandigarh. Journal of Family Medicine and Primary Care 2017; 6(2): 405-410. Retrieved from https://pubmed.ncbi.nlm.nih.gov/29302555/

12. Bhasin SK, Sharma R, Saini NK. Depression, Anxiety and Stress among Adolescent Students Belonging to Affluent Families: A School-based Study. Indian Journal of Pediatrics 2010; 77: 161-165. Retrieved from https:// pubmed.ncbi.nlm.nih.gov/19936655/

13. Manikandan, Nirmala Devi S. A Study on Stress Among Adolescent Learners. Scholarly Research Journal for InterdisciplinaryStudy 2015;2(16): 2725-2730. Retrieved from http://oaji.net/articles/2015/1174-1426244624. pdf

14. Preeti B, Singh K, Kumar R. Study of depression, anxiety and stress among school going adolescents. Indian J Psy Socl Work 2017; 8: 6-9. Retrieved from https:// pswjournal.org/index.php/ijpsw/article/view/4

15. Rebellow MR, Asir SD. Stress among School Going Adolescents. IOSR Journal of Humanities And Social Science (IOSR-JHSS) 2017: 77-79. Retrieved from https:// www.iosrjournals.org/iosr-jhss/papers/Conf.17004/ Volume-3/14.\%2077-79.pdf

16. Deb, Sibnath, Chatterjee et al. Anxiety among high school students in India: comparisons across gender, school type, social strata, and perceptions of quality time with parents. Australian Journal of Educational and Developmental Psychology 2010: 10(1): 18-31. Retrieved from https://eprints.qut.edu.au/33012/

17. Bhaskar R, Rudramma, Komala M. Study on Relationship between Stress and Adjustment among Adolescents. International Journal of Interdisciplinary and Multidisciplinary Studies (IJIMS). 2014; 2(1): 6267. Retrieved from: http://www.ijims.com/uploads/ 8e644896b852b0938acf10.pdf

18. Das JK, Salam RA, Lassi ZSet al. Interventions for
Adolescent Mental Health: An Overview of Systematic Reviews. The Journal of adolescent health 2016: 59 (4S). S49-S60. DOI: https://doi.org/10.1016/j.jadohealth. 2016.06.020

19. Rabindran, Gedam DS. Adolescent Suicide- A Rising Trend. Int J Med Res Rev 2016; 4(2): 142-143. DOI: 10.17511/ijmrr.2016.i02.024 retrieved from https:// ijmrr.medresearch.in/index.php/ijmrr/article/view/449 